\title{
Nasogastric administration of osimertinib suspension for an epidermal growth factor receptor-mutated lung cancer causing an esophageal stricture: case report
}

\author{
Nozomi Tani ${ }^{1}$, Saki Takatsuka ${ }^{1}$, Nobutaka Kataoka ${ }^{1}$, Yusuke Kunimatsu ${ }^{1}$, Rei Tsutsumi $^{1}$, Izumi Sato ${ }^{1}$, \\ Mai Tanimura ${ }^{1}$, Takayuki Nakano ${ }^{1}$, Keiko Tanimura ${ }^{1}$, Daishiro Kato ${ }^{2}$, Takayuki Takeda ${ }^{1} \wedge$ \\ ${ }^{1}$ Department of Respiratory Medicine, Japanese Red Cross Kyoto Daini Hospital, Kyoto, Japan; ${ }^{2}$ Department of Thoracic Surgery, Japanese Red \\ Cross Kyoto Daini Hospital, Kyoto, Japan \\ Correspondence to: Takayuki Takeda, MD, PhD. Department of Respiratory Medicine, Japanese Red Cross Kyoto Daini Hospital, 355-5, Haruobi-cho, \\ Kamanza-dori, Marutamachi-agaru, Kamigyo-ku, Kyoto 602-8026, Japan. Email: dyckw344@yahoo.co.jp.
}

\begin{abstract}
An esophageal stricture is an abnormal esophageal narrowing, usually caused by esophageal diseases and rarely by lung cancer. They cause malnutrition, performance status (PS) deterioration, and difficulty in the oral administration of antitumor drug tablets. A 78-year-old female patient with lung adenocarcinoma, harboring an epidermal growth factor receptor $(E G F R)$-sensitizing mutation, experienced dysphagia due to an esophageal stricture caused by retrotracheal lymph node metastases. Osimertinib is a third-generation EGFR-tyrosine kinase inhibitor that is efficacious against EGFR-sensitizing mutations. The esophageal stricture hampered food intake and oral administration of osimertinib, causing severe malnutrition and deterioration to PS 3. Esophagogastroduodenoscopy (EGD) revealed severe and entire circumferential stenosis ( $7 \mathrm{~cm}$ in length) of the upper esophagus without mucosal abnormality. A nasogastric tube was inserted under EGD guidance, and an osimertinib suspension was administered accordingly: a tablet containing $80 \mathrm{mg}$ of osimertinib was suspended in $50 \mathrm{~mL}$ of sterile hot water $\left(55^{\circ} \mathrm{C}\right)$ for ten minutes, and the suspension was administered through a nasogastric tube once daily. Dysphagia improved 15 days after the introduction of osimertinib. After 21 days, the patient could take foods and drugs orally, and her PS improved to 1 . Administering an osimertinib suspension via a nasogastric tube was a viable option in managing esophageal strictures in patients with EGFR-sensitizing mutations.
\end{abstract}

Keywords: Adenocarcinoma; epidermal growth factor receptor (EGFR); esophageal stricture; nasogastric tube; osimertinib; case report

Submitted Apr 18, 2021. Accepted for publication Jun 01, 2021.

doi: 10.21037/apm-21-940

View this article at: https://dx.doi.org/10.21037/apm-21-940

\section{Introduction}

An esophageal stricture is an abnormal esophageal narrowing, usually caused by esophageal diseases and rarely by lung cancer. Epidermal growth factor receptor $(E G F R)$ mutations are the most frequent oncogenic driver mutations in lung adenocarcinoma, and EGFR-tyrosine kinase inhibitors (TKIs) are the mainstay of treatment. Osimertinib is a third-generation EGFR-TKI that is efficacious against $E G F R$-sensitizing mutations. It has been demonstrated to be superior to first-generation EGFRTKIs (1). However, patients with esophageal strictures experience dysphagia, making the administration of tablet medications difficult in such cases.

^ ORCID: 0000-0002-8375-6940. 

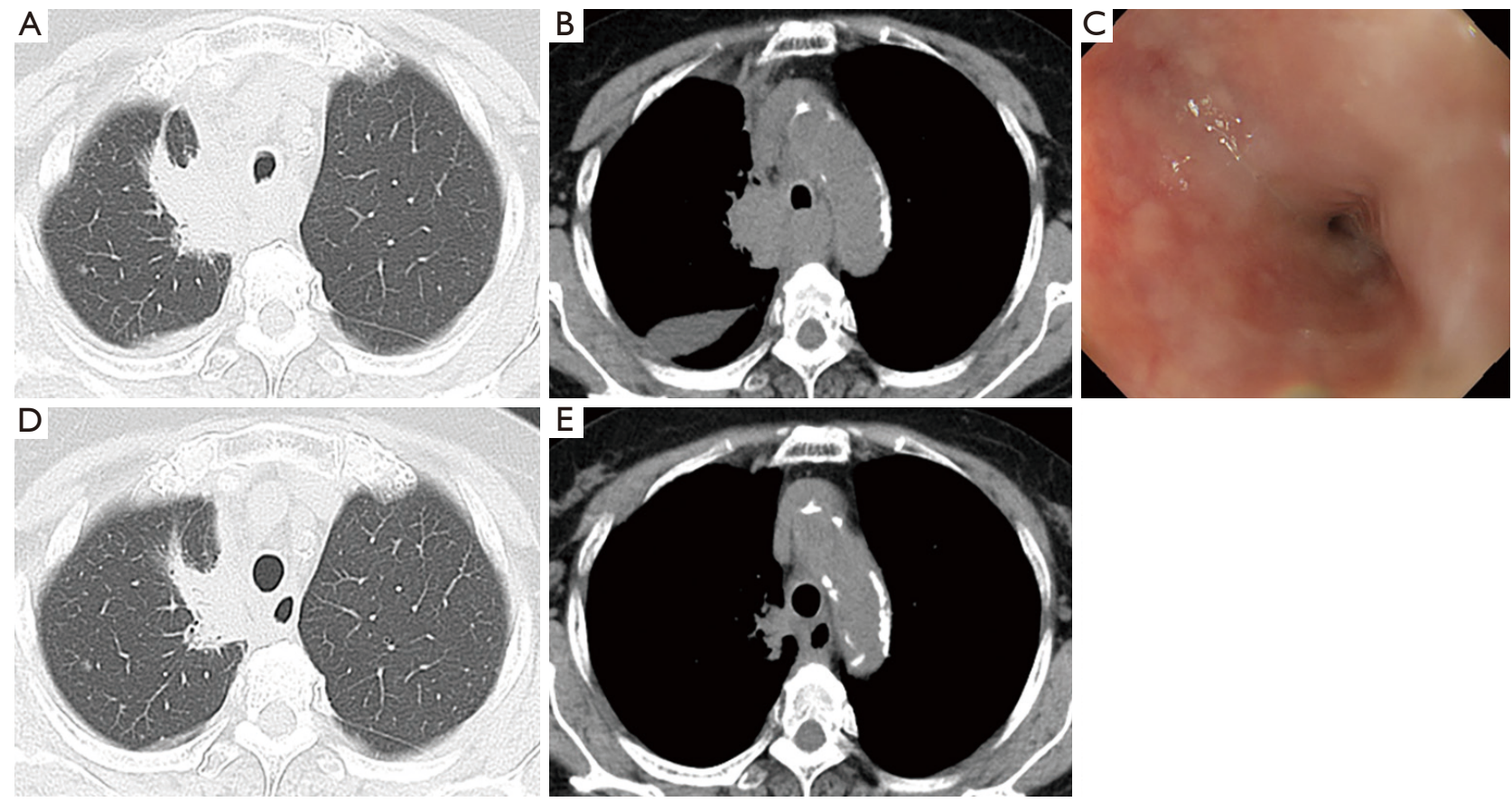

Figure 1 The images before and after osimertinib suspension treatment. (A) Computed tomography prior to treatment suggested lung cancer in the right upper lobe. (B) Computed tomography prior to treatment demonstrated mediastinal lymph node metastases, amongst which the retrotracheal lymph node metastases caused an esophageal stricture, as well as carcinomatous pleuritis.

(C) Esophagogastroduodenoscopy prior to treatment indicated a severe external and entire circumferential stenosis in the upper esophagus.

(D) Computed tomography obtained 21 days after osimertinib suspension administration demonstrated stable disease in the primary lesion.

(E) Computed tomography obtained 21 days after osimertinib suspension administration demonstrated partial response in mediastinal lymph node metastases, including those to retrotracheal lymph nodes.

We present a patient with adenocarcinoma of the lung harboring $E G F R$-sensitizing mutation, who presented an esophageal stricture, successfully treated with osimertinib suspension via a nasogastric tube. We present the following case in accordance with the CARE reporting checklist (available at https://apm.amegroups.com/article/ view/10.21037/apm-21-940/rc).

\section{Case presentation}

All procedures performed in this study were in accordance with the ethical standards of the institutional and/or national research committee(s) and with the Helsinki Declaration (as revised in 2013). Written informed consent was obtained from the patient for publication of this case report and accompanying images. A copy of the written consent is available for review by the editorial office of this journal.
A 78-year-old woman was referred to our department for dyspnea and dysphagia, which did not respond to antiacid treatment for four weeks. The patient was a never smoker who had no past medical history or family history of malignancy. Physical examination revealed no significant findings including lymphadenopathy. Chest X-ray and computed tomography results suggested lung cancer in the right upper lobe with mediastinal lymph node metastases and carcinomatous pleuritis (Figure 1A,1B). Semi-flexible thoracoscopy under local anesthesia demonstrated lung adenocarcinoma with EGFR mutation (L858R point mutation in exon 21) and cT2aN3M1a clinical-stage IVA. Osimertinib was the standard first-line treatment. However, the esophageal stricture, caused by retrotracheal lymph node metastases (Figure 1B), hampered the oral administration of the osimertinib tablet. The esophageal stricture also caused severe malnutrition, which did not respond to the peripheral parenteral nutrition, and deterioration to 
performance status (PS) 3. Esophagogastroduodenoscopy (EGD) with a distal end diameter of $5.4 \mathrm{~mm}$ revealed severe and entire circumferential stenosis $(7 \mathrm{~cm}$ in length, through which the EGD could pass) of the upper esophagus without mucosal abnormality (Figure 1C). Self-expandable metallic esophageal stent deployment could be one option, which was not adopted in the current case considering the risk of stent dislocation after shrinkage of lymph node metastases by osimertinib. Then, a nasogastric tube was inserted under EGD guidance and an osimertinib suspension was administered accordingly: a tablet containing $80 \mathrm{mg}$ of osimertinib was suspended in $50 \mathrm{~mL}$ of sterile hot water $\left(55^{\circ} \mathrm{C}\right)$ for 10 minutes, and the suspension was administered through a nasogastric tube once daily. Percutaneous endoscopic gastrostomy was not performed since the patient refused the procedure. No adverse events were observed during the treatment period. After 21 days, the response to Osimertinib was evaluated. The primary lesion exhibited stable disease (Figure 1D), while the mediastinal lymph node metastases, including those that infiltrated the retrotracheal lymph nodes and caused the esophageal stricture, exhibited a partial response (Figure 1E). Dysphagia improved 15 days after the introduction of osimertinib. After 21 days, the patient was able to take foods and osimertinib tablets orally, and her PS improved to 1.

\section{Discussion}

An esophageal stricture is an abnormal narrowing of the esophagus that induces painful or difficult swallowing. Cancerous strictures tend to cause more rapid symptoms progression than benign strictures. Esophageal strictures are usually caused by esophageal diseases such as esophageal cancer, eosinophilic esophagitis, gastroesophageal reflux disease, and radiation esophagitis following radiotherapy to the head and neck or chest. Esophageal strictures caused by lung cancer are rare.

EGFR-TKIs are the mainstay of treatment of lung cancer with $E G F R$-sensitizing mutations. However, swallowing medication "in tablet form" is difficult in patients with esophageal stricture. The availability of liquid medication through orogastric, nasogastric, or gastrostomy tubes, or as a drink is advantageous in such cases.

Since dysphagia is sometimes caused by brain metastases or leptomeningeal metastases in patients with lung cancer, EGFR-TKIs have been delivered in a suspension form via nasogastric tube (2-4). Esophageal strictures caused by lung cancer rarely occur. However, when it does, patients develop a poor PS due to malnutrition following dysphagia. Thus, the palliation of relentless symptoms arising from esophageal strictures is urgently needed. Although cytotoxic chemotherapy is not recommended in patients with poor PS, EGFR-TKIs are recommended due to the favorable response rate and progression-free survival as well as less toxic adverse event profiles (5). Among the EGFR-TKIs, osimertinib was more effective than the first-generation EGFR-TKIs (1). Ensuring the appropriate delivery of osimertinib to the patient is crucial.

The relative bioavailability and safety profiles of the various forms of gefitinib (tablet, dispersion-preparation drink, and nasogastric tube) have already been reported (6). The area under the plasma concentration-time curve, maximum drug concentration, and adverse event profile of the nasogastric tube-administered gefitinib dispersionpreparation group was similar to that of the whole tablet group. Although the efficacy of the osimertinib dispersion preparation or suspension has not been compared to its tablet form, the chemical formula and coating agents in gefitinib and osimertinib are similar. Moreover, the efficacy of the osimertinib suspension administered via nasogastric tube has been reported in a patient with leptomeningeal metastases (4).

Osimertinib is crucial in treating lung cancer patients with EGFR mutations. Moreover, its efficacy as a suspension drug has already been documented previously. Thus, administering the osimertinib suspension via nasogastric tube is an essential strategy in treating patients with EGFR mutations, who present with esophageal strictures, making the osimertinib tablet difficult to swallow.

\section{Acknowledgments}

Funding: None.

\section{Footnote}

Reporting Checklist: The authors have completed the CARE reporting checklist. Available at https://apm.amegroups. com/article/view/10.21037/apm-21-940/rc

Peer Review File: Available at https://apm.amegroups.com/ article/view/10.21037/apm-21-940/prf

Conflicts of Interest: All authors have completed the ICMJE uniform disclosure form (available at https://apm. amegroups.com/article/view/10.21037/apm-21-940/coif). 
The authors have no conflicts of interest to declare.

Ethical Statement: The authors are accountable for all aspects of the work in ensuring that questions related to the accuracy or integrity of any part of the work are appropriately investigated and resolved. All procedures performed in this study were in accordance with the ethical standards of the institutional and/or national research committee and with the Helsinki Declaration (as revised in 2013). Written informed consent was obtained from the patient for publication of this case report and accompanying images. A copy of the written consent is available for review by the editorial office of this journal.

Open Access Statement: This is an Open Access article distributed in accordance with the Creative Commons Attribution-NonCommercial-NoDerivs 4.0 International License (CC BY-NC-ND 4.0), which permits the noncommercial replication and distribution of the article with the strict proviso that no changes or edits are made and the original work is properly cited (including links to both the formal publication through the relevant DOI and the license). See: https://creativecommons.org/licenses/by-nc-nd/4.0/.

\section{References}

1. Soria JC, Ohe Y, Vansteenkiste J, et al. Osimertinib in

Cite this article as: Tani N, Takatsuka S, Kataoka N, Kunimatsu Y, Tsutsumi R, Sato I, Tanimura M, Nakano T, Tanimura K, Kato D, Takeda T. Nasogastric administration of osimertinib suspension for an epidermal growth factor receptormutated lung cancer causing an esophageal stricture: case report. Ann Palliat Med 2022;11(4):1542-1545. doi: 10.21037/apm21-940 untreated EGFR-mutated advanced non-small-cell lung cancer. N Engl J Med 2018;378:113-25.

2. Okuda T, Hayashi H, Fujita M, et al. Administration of gefitinib via nasogastric tube effectively improved the performance status of a patient with lung adenocarcinomaderived meningeal carcinomatosis. Int Canc Conf J 2014;3:211-4.

3. Suzumura T, Yonesaka K, Tsukada H, et al. Successful gefitinib treatment administration via gastrostomy tube in a patient with non-small cell lung cancer with dysphagia. BMJ Case Rep 2014;2014:bcr2013202705.

4. Takeda T, Itano H, Takeuchi M, et al. Osimertinib administration via nasogastric tube in an EGFR-T790Mpositive patient with leptomeningeal metastases. Respirol Case Rep 2017;5:e00241.

5. Inoue A, Kobayashi K, Usui K, et al. First-line gefitinib for patients with advanced non-small-cell lung cancer harboring epidermal growth factor receptor mutations without indication for chemotherapy. J Clin Oncol 2009;27:1394-400.

6. Cantarini MV, McFarquhar T, Smith RP, et al. Relative bioavailability and safety profile of gefitinib administered as a tablet or as a dispersion preparation via drink or nasogastric tube: results of a randomized, open-label, three-period crossover study in healthy volunteers. Clin Ther 2004;26:1630-6. 